\title{
Strong HLA-DR expression in microsatellite stable carcinomas of the large bowel is associated with good prognosis
}

\author{
T Løvig*,', SN Andersen', L Thorstensen², CB Diep², GI Meling', RA Lothe² and TO Rognum' \\ 'Institute of Forensic Medicine, The National Hospital, University of Oslo, 0027 Oslo, Norway; ${ }^{2}$ Department of Genetics, Institute for Cancer Research, The \\ Norwegian Radium Hospital, 0310 Oslo, Norway
}

Progression of colorectal cancer may follow either of two main genetic routes: the chromosome- or microsatellite-instability pathways. Association between the patients' prognosis and microsatellite instability has been questioned. Improved survival has previously been found in patients with expression of HLA-DR antigens on their tumour cells. In this study, the expression of HLA-DR antigen was investigated by immunohistochemistry in 357 large bowel carcinomas stratified by microsatellite instability status. Sixteen per cent of the tumours showed strong HLA-DR expression and 35\% had weak DR expression. We confirmed that patients with strong positive HLA-DR staining had improved survival $(P<0.00 \mathrm{I})$ compared to patients with no HLA-DR expression. Strong epithelial HLA-DR staining was significantly associated with high level of microsatellite instability $(P<0.00 \mathrm{I})$. In the subgroup of tumours with characteristics typical of the chromosomal instability phenotype, i.e. in microsatellite-stable tumours, the patients positive for the HLA-DR determinants showed better survival than those without HLA-DR expression. The protective effect of HLA-DR expression on survival was confirmed by multivariate analysis, both in the whole patient group and in the microsatellite-stable/microsatellite instability-low group. This might be explained by enhanced T-cell mediated anti-tumour immune responses against tumour cells in the HLA-DR positive tumours. The finding of better patient survival in the subgroup of strong HLA-DR positive microsatellite-stable tumours may have clinical implications for these patients.

British Journal of Cancer (2002) 87, 756 -762. doi: I0.1038/sj.bjc.6600507 www.bjcancer.com

(c) 2002 Cancer Research UK

Keywords: colorectal neoplasms; HLA-DR; immunohistochemistry; microsatellite instability; survival

Primary colorectal tumours may be divided into two main groups related to the genetic profile of the tumour (Kinzler and Vogelstein, 1996). Tumours with chromosome instability (CIN) reveal high rates of chromosome losses and gains, whereas tumours with microsatellite instability (MSI) show genome-wide changes in repetitive sequences due to defects in the DNA mismatch repair system. Most tumours in hereditary non-polyposis colorectal cancer (HNPCC), and about $15 \%$ of sporadic colorectal carcinomas show MSI (Aaltonen et al, 1993; Lothe et al, 1993). MSI leads to the accumulation of deletion and insertion of nucleotides at simple repeat sequences. The clinical and pathological features of colorectal cancers showing high degree of MSI (MSI-H) are proximal location, poor differentiation, mucinous phenotype, high density of lymphocyte infiltration, diploid DNA content, reduced invasiveness, female preponderance and multiplicity (Lothe et al, 1993; Kim et al, 1994; Ruschoff et al, 1995; Messerini et al, 1997; Jass et al, 1998; Thibodeau et al, 1998). High density of tumour infiltrating lymphocytes (TIL) are found in MSI-H colorectal cancers, whereas it is only infrequently observed in MSI-L and MSS tumours (Jass et al, 1998; Smyrk et al, 2001). Recently, two studies have identified significantly more cytotoxic lymphocytes (CD3, CD8 and TIA-1) and a higher rate of cells undergoing apoptosis in MSI-H colorectal carcinomas than in MSI-L and MSS (Dolcetti et al, 1999; Michael-Robinson et al,

*Correspondence: T Løvig; E-mail: tone.lovig@labmed.uio.no

Received 4 February 2002; revised 3 I May 2002; accepted 25 June 2002
2001). Furthermore, patients with MSI-H tumours and a high content of activated cytotoxic lymphocytes showed improved overall survival (Guidoboni et al, 2001). Some studies have reported improved survival among colorectal cancer patients with microsatellite unstable tumours (Lothe et al, 1993; Thibodeau et al, 1993; Bubb et al, 1996; Lukish et al, 1998; Halling et al, 1999; Johannsdottir et al, 1999; Massa et al, 1999; Elsaleh et al, 2000; Gryfe et al, 2000; Hemminki et al, 2000; Wright et al, 2000; Ward et al, 2001; Watanabe et al, 2001), while others have not (Messerini et al, 1997; Senba et al, 1998; Feeley et al, 1999; Salahshor et al, 1999; Curran et al, 2000).

The major histocompatibility complex (MHC) in humans plays an important role in various kinds of immune reactions, including antigen presentation, cytotoxic response, and immune recognition. The MHC encodes for three classes of cell antigens: class I (HLA-A, $-\mathrm{B},-\mathrm{C})$, class II (HLA-DR, -DQ, -DP) and class III (Klein and Sato, 2000). HLA-DR antigen expression is usually not present in the epithelium of the large bowel, but may be turned on in inflammatory disorders, such as ulcerative colitis (Rognum et al, 1987), Crohn's disease and in colorectal tumours (Rognum et al, 1983; Gutierrez et al, 1987; Norheim Andersen et al, 1993; Chang and Sohn, 1995; Lazaris et al, 1995; Morita et al, 1995; Kunihiro et al, 1998). HLA-DR antigen expression on tumour cells is a marker of good prognosis in large bowel carcinomas (Gutierrez et al, 1987; Norheim Andersen et al, 1993; Lazaris et al, 1995; Morita et al, 1995; Kunihiro et al, 1998).

In a large series of primary colorectal carcinomas, stratified as MSI-H and MSS/MSI-L, we have analysed the epithelial expression 
of HLA-DR and addressed the association with clinical and pathological variables.

\section{MATERIALS AND METHODS}

\section{Patients}

The study was based on two series of tumours collected from hospitals in the Oslo and Akershus region. The first series of 100 large bowel carcinomas from 100 patients were operated on between 1978 and 1982, and have previously been studied according to HLA-DR expression (Norheim Andersen et al, 1993). The second consecutive series of tumours from 257 patients with primary colorectal cancer were collected during the period 1987-1989. The clinicopathological characteristics of the patients are given in Table 1. The median age at diagnosis was 67 years for males (range 26-94) and 69 years for females (range 24-92). Survival was recorded from the date of resection of the tumour until death or until the censor date (1 July 1995 for the first series of 100 patients and 1 July 1999 for the second series of 257 patients). Patients that died within 30 days after operation were censored and cancer-specific deaths have been recorded from hospital and post-mortem reports. All of the patients underwent surgery alone as the curative treatment, except for a few patients with rectal cancers who also received postoperative radiation therapy. Two patients in the second series of tumours fulfil the Amsterdam criteria for HNPCC, one case being MSS and the other MSI-H. For the first series of tumours information about Amsterdam criteria is not available.

\section{HLA-DR immunohistochemistry}

Tissue slices from each of the 257 tumours in the second series were fixed in cold $96 \%$ ethanol and processed for paraffin embedding as previously described (Brandtzaeg, 1974). Sections cut at $6 \mu \mathrm{m}$ were dewaxed and subjected to immunofluorescence staining and one section was stained by a routine method (HAS) containing haematoxylin, azofloxin and saffron. A murine monoclonal antibody to a non-polymorphic human HLA-DR antigen was applied in an indirect three-step immunofluorescence method as described previously (Norheim Andersen et al, 1993). The method included affinity purified biotinylated horse anti mouse IgG and fluorecein isothiocyanate (FITC)-labelled avidin.

The epithelial staining for HLA-DR antigens in the carcinomas was evaluated by a Leitz Aristoplan fluorescence microscope (Leica). The tumours were divided into four groups according to the percentage of positive tumour epithelium, $0-5,5-20$, $20-50$ and $>50 \%$, respectively. In the further analysis, the samples with $0-5 \%$ positive cells were considered negative, whereas samples with $5-50 \%$ positive cells were classified as weak HLA-DR positive, and those $>50 \%$ as strong HLA-DR positive. Three sections from 97 tumours and two sections from 224 tumours were investigated, while only one section was investigated in the remaining 36 cases. The same investigator (SNA) was responsible for the fluorescence scoring throughout both series of tumours studied. The HLA-DR staining was scored blindly in view of MSI status of the tumour. Since the scoring procedure showed good inter- and intra-observer reproducibility in the first study of 100 carcinomas (Norheim Andersen et al,

Table I Epithelial HLA-DR expression in relation to clinicopathological variables and MSI status in 357 primary colorectal carcinomas

\begin{tabular}{|c|c|c|c|c|c|}
\hline & \multirow[b]{2}{*}{ Total number } & \multicolumn{3}{|c|}{ HLA-DR expression ${ }^{a}$} & \multirow[b]{2}{*}{$P$} \\
\hline & & Negative (\%) & Weak (\%) & Strong (\%) & \\
\hline Age (mean \pm S.D.) & 357 & $67.4 \pm 12.2$ & $68.2 \pm 12.6$ & $67.1 \pm 13.8$ & $0.924^{c}$ \\
\hline \multicolumn{6}{|l|}{ Sex } \\
\hline Females & 173 & $77(45)$ & $65(38)$ & $31(18)$ & \\
\hline Males & 184 & $99(54)$ & $58(32)$ & $27(15)$ & $0.214^{\mathrm{b}}$ \\
\hline \multicolumn{6}{|l|}{ Tumour site } \\
\hline Right colon & 108 & $42(39)$ & $35(32)$ & $31(29)$ & \\
\hline Left colon ${ }^{d}$ & 93 & $53(57)$ & $31(33)$ & $9(10)$ & $0.00 l^{b}$ \\
\hline Rectum & 156 & $81(52)$ & $57(37)$ & $18(12)$ & \\
\hline \multicolumn{6}{|l|}{ Dukes' stage } \\
\hline A & 60 & $26(43)$ & $20(33)$ & $14(23)$ & \\
\hline B & $|5|$ & $71(47)$ & $56(37)$ & $24(16)$ & \\
\hline C & 100 & $49(49)$ & $33(33)$ & $18(18)$ & \\
\hline$D$ & 46 & $30(65)$ & $14(30)$ & $2(4)$ & $0.141^{b}$ \\
\hline \multicolumn{6}{|l|}{ Histological grade } \\
\hline Well differentiated & 26 & $15(58)$ & II (42) & $0(0)$ & \\
\hline Moderately differentiated & 279 & $136(49)$ & $104(37)$ & $39(14)$ & \\
\hline Poorly differentiated & 52 & $25(48)$ & $8(15)$ & $19(37)$ & $<0.001^{b}$ \\
\hline \multicolumn{6}{|l|}{ TIL count } \\
\hline (mean \pm s.d.) & 254 & $16.7 \pm 9.6$ & $18.1 \pm 1 \mid .1$ & $32.3 \pm 25.6$ & $<0.001^{c}$ \\
\hline Median & & 14.0 & 15.0 & 25.5 & \\
\hline \multicolumn{6}{|l|}{ Ploidy } \\
\hline Diploid & 132 & $56(42)$ & $39(30)$ & $37(28)$ & \\
\hline Aneuploid & 225 & $120(53)$ & $84(37)$ & $21(9)$ & $<0.001^{b}$ \\
\hline \multicolumn{6}{|l|}{ MSI status ${ }^{\mathrm{e}}$} \\
\hline MSS/MSI-L & 306 & $158(52)$ & $113(37)$ & $35(11)$ & \\
\hline MSI-H & 40 & II (28) & $8(20)$ & $21(53)$ & $<0.001^{\mathrm{b}}$ \\
\hline Total & 357 & $176(49)$ & $123(35)$ & $58(16)$ & \\
\hline
\end{tabular}

aPer cent of cells showing epithelial staining; negative $0-5 \%$, weak $5-50 \%$ and strong more than $50 \%$. 'Pearson's $\chi^{2}$ test. 'Kruskal-Wallis test. 'Sigmoideum, descendens and left flexure. 'Data missing on I I tumours. 
1993), such tests were not included in the evaluation of the 257 tumours.

\section{Histopathological analysis of the tumours}

For all tumours, histopathological type and degree of differentiation (WHO classification (Jass and Sobin, 1989)), as well as clinicopathological stage, have been published previously (Meling et al, 1991; Rognum, 1991). In the second series of tumours, tumour infiltrating lymphocytes (TIL) were identified by light microscopy on HASstained sections as cells with the morphology of lymphocytes, seen within the tumour epithelium. TIL's were counted in 10 high power fields from each tumour, since a stable mean of number of TIL per high power field was achieved in the tumours after counting 10 fields. Enumeration of TIL's was performed by the same experienced investigator (SNA) throughout the study.

\section{MSI status}

The MSI status of the 100 tumours in the first series were analysed by the two mononucleotide repeats, BAT- 25 and BAT26, which are robust markers for MSI-H detection (Loukola et al, 2001; Zhou et al, 1998). Tumours with mutation in both markers were defined MSI-H (10 cases) and the rest were put in the MSS/MSI-L group.

MSI status in the second series was available in 246 of the 257 tumours (Lothe et al, 1993; Thorstensen et al, 2001; Diep et al, 2002, unpublished). The tumours have been analysed with BAT25 and BAT-26, in addition to a total of 19 dinucleotide repeats. DNA from each tumour, except from five tumours, was informative in at least five (median 18, range 5-21) of the loci analysed (Thorstensen et al, 2001; Diep et al, 2002, unpublished). The 30 tumours with instability in $\geqslant 30 \%$ of the microsatellite loci analysed, or with mutation in both BAT-25 and BAT-26 were defined as MSI-high (MSI-H). The 32 tumours with instability in at least one locus and less than $30 \%$ of the loci was MSI-low
(MSI-L), whereas the 184 tumours without microsatellite instability was classified as microsatellite stable (MSS), according to the consensus criteria for classification of MSI (Boland et al, 1998).

\section{Statistics}

Statistical analyses were conducted using the SPSS software v10.0. Comparisons between categorical variables were performed using Pearson's $\chi^{2}$ analysis. Continuous variables (age and TIL count) were analysed using the non-parametric Kruskal-Wallis test. Survival curves were estimated by the Kaplan-Meier method, and differences were assessed using the log rank test. To estimate the effect of different factors on survival, a multivariate analysis was performed using the Cox proportional-hazards method. The following variables were included in the analysis: age, sex, Dukes' stage, tumour site, histological grade, DNA ploidi pattern, HLADR staining and MSI status. A probability value of less than 0.05 was considered statistically significant.

\section{RESULTS}

\section{HLA-DR expression in relation to MSI status and clinicopathological variables}

Epithelial HLA-DR expression in varying degrees was found in 181 of the $357(51 \%)$ tumours investigated (Figure 1). Fifty-eight (16\%) showed strong HLA-DR expression, whereas 123 (35\%) had weak DR expression. HLA-DR expression in relation to MSI status and clinicopathological variables is shown in Table 1. Strong HLA-DR expression occurred in 21 of 40 (53\%) of MSI-H tumours, whereas the same was found in only 35 of $306(11 \%)$ MSS/MSI-L tumours $(P<0.001)$. Furthermore, tumours with DR expression were related to other variables typical for MSI-H tumours. That is, tumours with strong HLA-DR expression were significantly more often poorly differentiated $(P<0.001)$, had more often a diploid DNA pattern $(P<0.001)$ and were more frequent
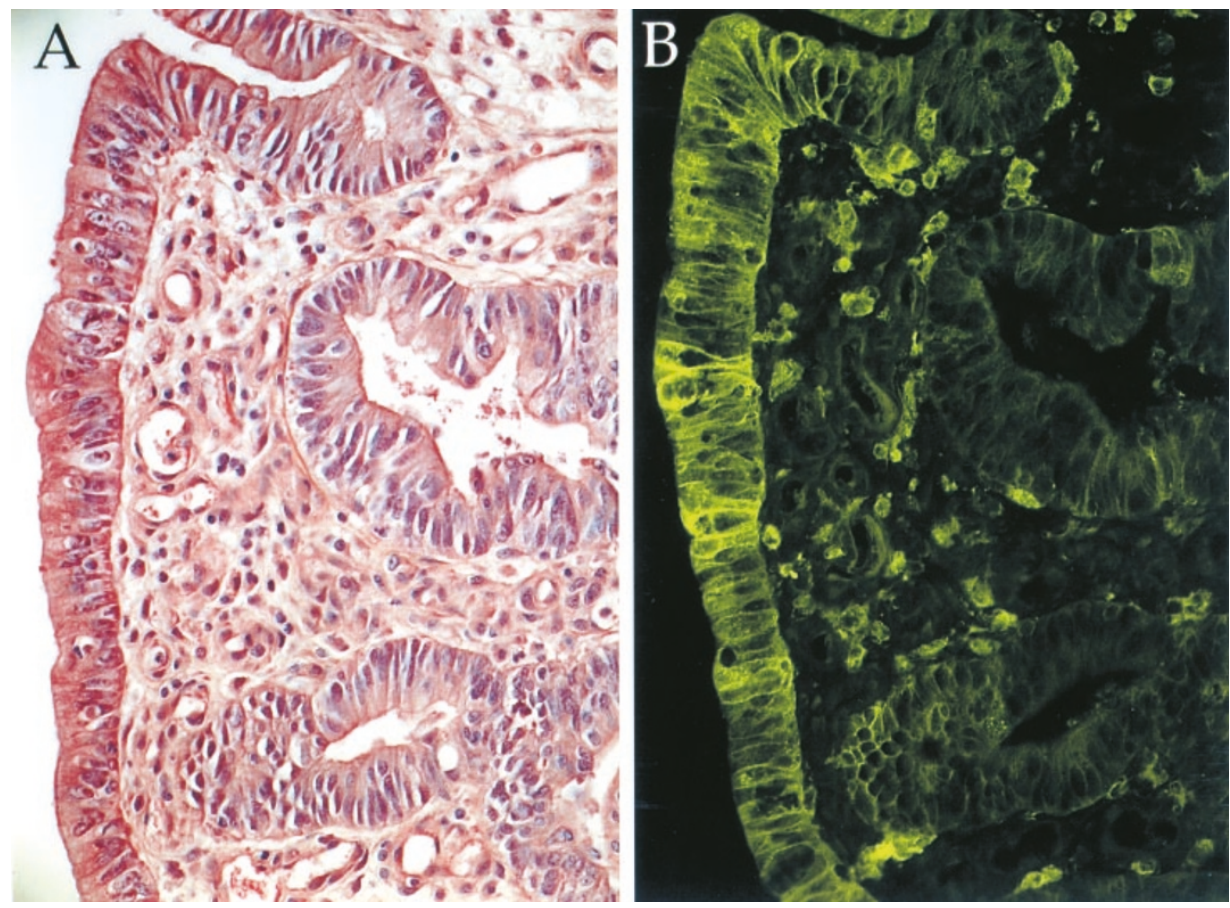

Figure I Moderately differentiated large bowel carcinoma with strong HLA-DR expression. (A) HAS staining and (B) adjacent section stained green for HLA-DR determinants. 
located in the right colon than in the left colon or rectum $(P=0.001)$ (Table 1$)$. Left-sided and rectal tumours had an equal distribution of strong DR expression. Strong DR positive tumours had significantly higher number of TIL than tumours with weak or no DR-staining $(P<0.001)$. There was no association with HLADR expression according to Dukes' stages $(P=0.141)$.

\section{HLA-DR expression and survival analysis}

During the follow-up period of $10-13$ years there were 138 cancer specific deaths in the group of 357 patients included in the study. Dukes' stage is significantly associated with patient survival $(P<0.001, \log$ rank test for trend). There is a better patient survival in MSI-H tumours compared to MSS/MSI-L tumours, as shown by both univariate Kaplan - Meier method $(P=0.004$, log rank test for trend) and by multivatiate analysis (HR $0.44,95 \%$ CI: $0.20-0.96$, data not shown). Analysis of survival according to HLA-DR in the whole group of patients showed significant differences between the three patterns of tumour HLA-DR expression $(P<0.001)$ (Figure 2 ). Survival was significantly better in patients with tumours showing HLA-DR expression compared to those with no DR expression, both in the weak- and strong DR expression group $(P=0.025$ and $P<0.001$, respectively). Stratified survival analysis according to sex showed that both males and females with DR-positive tumours had better survival compared to those without $(P<0.001$, data not shown). According to tumour site, stratified analysis showed that patients with HLA-DR positive tumours located in colon had better survival, whereas for patients with rectal tumours DR expression had no influence on patient survival $(P<0.001$ and $P=0.421$, respectively; data not shown). Stratified survival analysis according to tumour MSI status, histological grade and ploidi showed that expression of HLA-DR in tumours was associated with better survival in the subgroups of patients with characteristics typical for the chromosome instability (CIN) phenotype, i.e. MSS/MSI-L tumours. Patients with tumours expressing HLA-DR showed significantly better survival when the tumours were MSS/MSI-L $(P=0.001)$ (Figure 3). The same was true for patients with tumours that had aneuploid DNA content $(P=0.003)$ or were moderately differentiated $(P=0.002)$ (Figure 3$)$. The good prognosis in the patients with strong HLA-DR positive MSS tumours is not due to higher TIL count in these tumours, as they had a median TIL count of 16 .

Survival analysis stratified according to Dukes' stage showed an overall significant difference in survival ( $P=0.003$, data not shown).

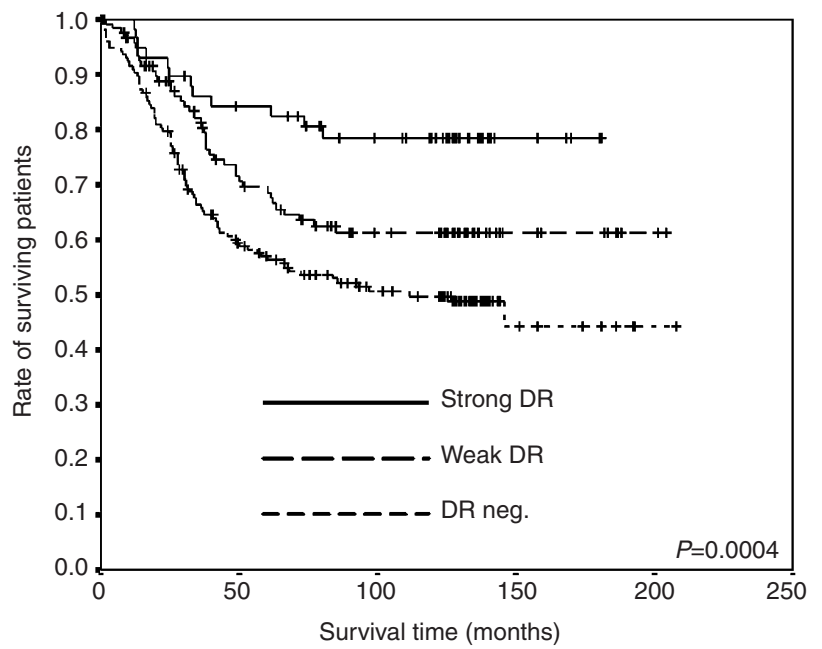

Figure 2 Survival analyses (cancer-related Kaplan-Meier plots) of patients with different degrees of HLA-DR expression. $n=58$ with strong DR expression, $n=123$ with weak DR expression and $n=176$ DR negative.
Multivariate analysis using Cox proportional hazard regression analysis confirmed that both weak and strong HLA-DR expression

A

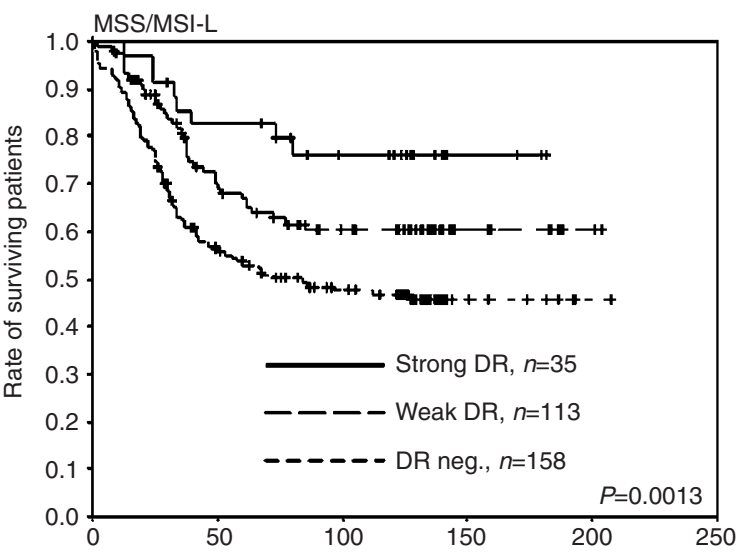

B

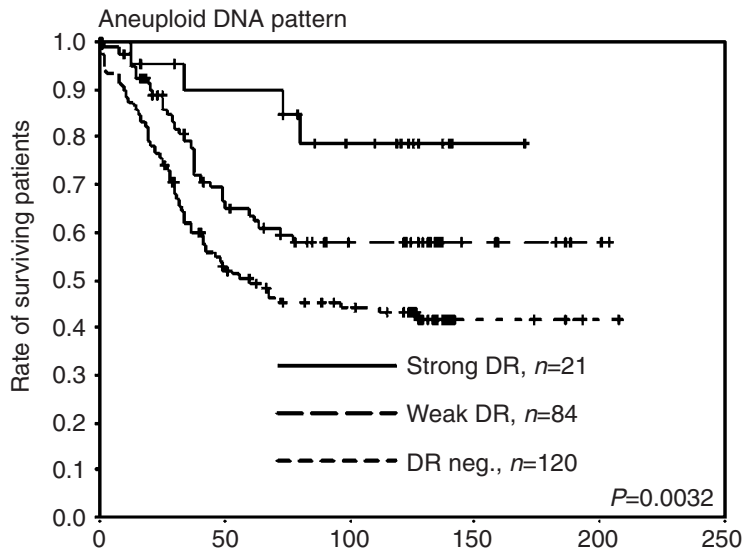

C

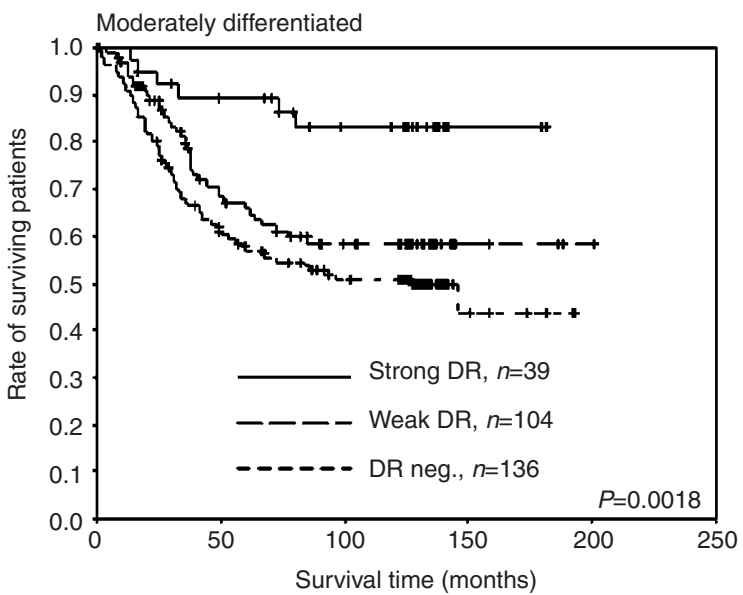

Figure 3 Survival analysis (cancer-related Kaplan-Meier plots) of patients in relation to HLA-DR expression and different variables. (A) Patients with MSS/MSI-L tumours, (B) patients with aneuploid tumours and (C) patients with moderately differentiated tumours. When considering strong DR expression compared to no expression, the $P$-value for MSS/ MSI-L tumours was $P=0.0024, P=0.0050$ for aneuploid tumours, and $P=0.0006$ for moderately differentiated tumours. 
had an overall protective effect on survival (Table 2). When analysing only the MSS/MSI-L group, the protective effect of DRexpression is still significant (strong HLA-DR expression: HR 0.38, 95\% CI: $0.175-0.812$ and weak HLA-DR expression: HR 0.68, 95\% CI: $0.458-0.998$; data not shown).

\section{DISCUSSION}

In the present study we found that strong epithelial HLA-DR expression was highly associated with the MSI-H phenotype. Thus, $53 \%$ of the MSI-H tumours were strong HLA-DR positive, vs $11 \%$ in the MSS/MSI-L group. Because of the strong association between MSI-H tumours and HLA-DR expression, significant correlation was also demonstrated between DR expression and tumours with right-sided location, poor differentiation and diploid DNA pattern, which are the characteristics typical for colorectal tumours following the MSI pathway (Lothe et al, 1993; Kim et al, 1994; Ruschoff et al, 1995; Messerini et al, 1997; Jass et al, 1998; Thibodeau et al, 1998). Strong HLA-DR positive tumours also had a higher TIL count than the other two groups. The presence of an inflammatory reaction in the form of TIL is most frequently found in MSI-H carcinomas (Jass et al, 1998; Smyrk et al, 2001). No association was found between Dukes' stage and HLA-DR expression, which is consistent with previous studies (Lazaris et al, 1995; Kunihiro et al, 1998).

The MSI-H tumour phenotype is caused by defects in the DNA mismatch repair machinery, and stretches of repetitive sequences are prone to mutations. When such repeats are present in the coding region, mutations may cause disturbances in normal cellular control. Indeed, frameshift mutations in MSI-H tumours have been reported for several downstream target genes (Ionov et al, 1993; Thorstensen et al, 2001). The resulting shift in the reading frame of the genes gives rise to syntheses of truncated proteins that have lost all or part of their function. These antigenic peptides could elicit specific anti-tumour immune responses potentially effective in limiting tumorigenesis. This hypothesis is supported by the fact that there is a significant increase of the pronounced inflammatory reaction in the MSI-H tumours. Recently, two studies have identified the majority of TIL in MSI-H tumours as CD8+ T-cells, the number being higher than in MSS tumours (Dolcetti et al, 1999; Michael-Robinson et al, 2001). The number and distribution of infiltrating CD4+ lymphocytes were similar in MSI and MSS tumours (Dolcetti et al, 1999). However, our finding of HLA-DR expression in $53 \%$ of the MSI-H tumours, indicate that this might be an important part of the ongoing immune activation supposed to be present in MSI-H tumours. The abnormal peptides produced by MSI-H tumours may be presented to CD4+ T-cells by the HLADR molecules expressed on the cell surface. In fact, one recent study has identified a patient with an HLA-DR restricted CD4+ T-cell response against a TGF $\beta$ RII frameshift peptide (Sæterdal et $a l, 2001)$. The tumour had heterogeneous HLA-DR expression with prominent CD4+ T-cell infiltration in areas positive for HLA-DR antigen, whereas relatively few cytotoxic CD8+ T-cells were present. This indicates local cytokine production and may be a direct manifestation of immune surveillance.

Patients with HLA-DR positive carcinomas showed significantly better overall survival than in patients with DR negative carcinomas, which is consistent with several other studies (Gutierrez et al, 1987; Norheim Andersen et al, 1993; Lazaris et al, 1995; Morita et al, 1995; Kunihiro et al, 1998). Quite surprisingly, stratified analyses of survival with respect to MSI status, differentiation, ploidi and tumour localisation disclosed that in MSS/MSI-L tumours, in tumours with aneuploid DNA pattern and in moderately differentiated tumours, strong HLA-DR expression turned out to be a marker for favourable prognosis (Figure 3A,B,C). However, HLADR expression in the poorly differentiated, diploid, MSI-H tumours had no influence on survival. The overall protective effect of the HLA-DR expression on survival was confirmed by the multi-
Table 2 Cox proportional hazard model. Hazard ratio (HR) with 95\% confidence interval $(95 \% \mathrm{Cl})$ for death from colorectal cancer in accordance with different factors

\begin{tabular}{lccc}
\hline Variable & HR & $\mathbf{9 5 \%} \mathbf{C l}$ & P-value \\
\hline Age at surgery & 1.01 & $0.99-1.03$ & $\mathrm{~ns}$ \\
Sex, female vs male & 0.99 & $0.70-1.45$ & $\mathrm{~ns}$ \\
Dukes' stage B vs A & 1.43 & $0.73-2.83$ & $\mathrm{~ns}$ \\
Dukes' stage C vs A & 2.87 & $1.47-5.61$ & $<0.0$ I \\
Dukes' stage D vs A & 20.88 & $10.24-42.57$ & $<0.01$ \\
Localisation, right colon vs left & 0.85 & $0.59-1.23$ & $\mathrm{~ns}$ \\
Histological grade, poorly & 1.65 & $1.04-2.64$ & 0.04 \\
$\quad$ differentiated vs mod./well & & & \\
Diploid vs aneuploid & 1.18 & $0.77-1.82$ & $\mathrm{~ns}$ \\
Weak DR expression vs none & 0.67 & $0.45-0.98$ & 0.04 \\
Strong DR expression vs none & 0.42 & $0.22-0.82$ & 0.01 \\
MSI-H vs MSS+MSI-L & 0.71 & $0.46-1.10$ & $\mathrm{~ns}$ \\
\hline
\end{tabular}

ns: not significant.

variate analysis. Also, when analysing only patients with MSS/MSIL tumours by multivariate analysis, HLA-DR expression had a positive impact on patient survival.

Tumours with the CIN phenotype (usually MSS) represent the majority of sporadic colorectal cancers and are characterised by high rates of chromosome losses and gains. The HLA complex is located on chromosome $6 \mathrm{p} 21$, a region infrequently gained in colorectal carcinomas (Bardi et al, 1993; de Angelis et al, 1999; Rooney et al, 1999). The increased level of HLA- DR expression detected in $11 \%$ of the MSS tumours is not likely to be explained by a gain of chromosome $6 \mathrm{p}$.

Most studies report that there is an association between MSI-H tumours and improved disease outcome (Lothe et al, 1993; Thibodeau et al, 1993; Bubb et al, 1996; Lukish et al, 1998; Halling et al, 1999; Johannsdottir et al, 1999; Massa et al, 1999; Elsaleh et al, 2000; Gryfe et al, 2000; Hemminki et al, 2000; Wright et al, 2000; Ward et al, 2001; Watanabe et al, 2001). Furthermore, several studies have found that the degree of lymphocyte infiltration correlates with a better patient survival (Jass, 1986; di Giorgio et al, 1992; Ropponen et al, 1997; Naito et al, 1998). A recent study found that patients with MSI-H tumours with a high content of activated intra-tumour cytotoxic lymphocytes had better prognosis (Guidoboni et al, 2001). This finding supports the presence of an anti-tumour immune response in the MSI-H tumours, which probably explains the better prognosis in these patients. Patients with MSI-H tumours in the present study showed better survival than patients with MSS/MSI-L tumours. However, HLA-DR expression did not turn out to be of prognostic significance in the MSI-H tumours, although about half of the MSI-H tumours showed HLA-DR expression.

In conclusion, HLA-DR expression is most frequently found in carcinomas with MSI phenotype. However, it is also highly expressed in a small subgroup among tumours with the CIN phenotype. These patients have prolonged survival, indicating that HLA-DR expression may be an important part of the anti-tumour immune responses in colorectal carcinomas.

\section{ACKNOWLEDGEMENTS}

The authors wish to thank Kari Thorsdalen for excellent technical assistance. T Løvig is a Research Fellow and L Thorstensen is a Post Doctoral Fellow of the Norwegian Cancer Society (NCS). This study was also supported by additional grants from the NCS (RA Lothe, TO Rognum) and a grant from the Norwegian Foundation for Health and Rehabilitation (CB Diep). 


\section{REFERENCES}

Aaltonen LA, Peltomaki P, Leach FS, Sistonen P, Pylkkanen L, Mecklin JP, Jarvinen H, Powell SM, Jen J, Hamilton SR (1993) Clues to the pathogenesis of familial colorectal cancer. [see comments]. Science 260: 812-816

Bardi G, Pandis N, Fenger C, Kronborg O, Bomme L, Heim S (1993) Deletion of $1 \mathrm{p} 36$ as a primary chromosomal aberration in intestinal tumorigenesis. Cancer Res 53: $1895-1898$

Boland CR, Thibodeau SN, Hamilton SR, Sidransky D, Eshleman JR, Burt RW, Meltzer SJ, Rodriguez-Bigas MA, Fodde R, Ranzani GN, Srivastava S (1998) A National Cancer Institute Workshop on Microsatellite Instability for cancer detection and familial predisposition: development of international criteria for the determination of microsatellite instability in colorectal cancer. Cancer Res 58: $5248-5257$

Brandtzaeg P (1974) Mucosal and glandular distribution of immunoglobulin components. Immunohistochemistry with a cold ethanol-fixation technique. Immunology 26: $1101-1114$

Bubb VJ, Curtis LJ, Cunningham C, Dunlop MG, Carothers AD, Morris RG, White S, Bird CC, Wyllie AH (1996) Microsatellite instability and the role of hMSH2 in sporadic colorectalcancer. Oncogene 12: 2641-2649

Chang E-S, Sohn S-S (1995) Expression of HLA-DR Antigen in Large Bowel Carcinoma. I Korean Med Sci 10: 334-341

Curran B, Lenehan K, Mulcahy H, Tighe O, Bennett MA, Kay EW, O’Donoghue DP, Leader M, Croke DT (2000) Replication error phenotype, clinicopathological variables, and patient outcome in Dukes' B stage II (T3,N0,M0) colorectal cancer. Gut 46: 200-204

De Angelis PM, Clausen OP, Schjolberg A, Stokke T (1999) Chromosomal gains and losses in primary colorectal carcinomas detected by CGH and their associations with tumour DNA ploidy, genotypes and phenotypes. Br J Cancer 80: $526-535$

Di Giorgio A, Botti C, Tocchi A, Mingazzini P, Flammia M (1992) The influence of tumor lymphocytic infiltration on long term survival of surgically treated colorectal cancer patients. Int Surg 77: 256-260

Dolcetti R, Viel A, Doglioni C, Russo A, Guidoboni M, Capozzi E, Vecchiato N, Macri E, Fornasarig M, Boiocchi M (1999) High prevalence of activated intraepithelial cytotoxic T lymphocytes and increased neoplastic cell apoptosis in colorectal carcinomas with microsatellite instability. Am J Pathol 154: $1805-1813$

Elsaleh H, Powell B, Soontrapornchai P, Joseph D, Goria F, Spry N, Iacopetta B (2000) p53 gene mutation, microsatellite instability and adjuvant chemotherapy: impact on survival of 388 patients with Dukes' C colon carcinoma. Oncology 58: $52-59$

Feeley KM, Fullard JF, Heneghan MA, Smith T, Maher M, Murphy RP, O'Gorman TA (1999) Microsatellite instability in sporadic colorectal carcinoma is not an indicator of prognosis. J Pathol 188: $14-17$

Gryfe R, Kim H, Hsieh ET, Aronson MD, Holowaty EJ, Bull SB, Redston M, Gallinger S (2000) Tumor microsatellite instability and clinical outcome in young patients with colorectal cancer. [see comments]. N Engl J Med 342: $69-77$

Guidoboni M, Gafa R, Viel A, Doglioni C, Russo A, Santini A, Del Tin L, Macri E, Lanza G, Boiocchi M, Dolcetti R (2001) Microsatellite instability and high content of activated cytotoxic lymphocytes identify colon cancer patients with a favorable prognosis. Am J Pathol 159: $297-304$

Gutierrez J, Lopez-Nevot MA, Cabrera T, Oliva R, Esquivias J, Ruiz-Cabello F, Garrido F (1987) Class I and II HLA antigen distribution in normal mucosa, adenoma and colon carcinoma: relation with malignancy and invasiveness. Exp Clin Immunogenet 4: 144-152

Halling KC, French AJ, McDonnell SK, Burgart LJ, Schaid DJ, Peterson BJ, Moon-Tasson L, Mahoney MR, Sargent DJ, O’Connell MJ, Witzig TE, Farr Jr GH, Goldberg RM, Thibodeau SN (1999) Microsatellite instability and $8 \mathrm{p}$ allelic imbalance in stage B2 and C colorectal cancers. J Natl Cancer Inst 91: $1295-1303$

Hemminki A, Mecklin JP, Jarvinen H, Aaltonen LA, Joensuu H (2000) Microsatellite instability is a favorable prognostic indicator in patients with colorectal cancer receiving chemotherapy. Gastroenterology 119: $921-928$

Ionov Y, Peinado MA, Malkhosyan S, Shibata D, Perucho M (1993) Ubiquitous somatic mutations in simple repeated sequences reveal a new mechanism for colonic carcinogenesis. Nature 363: 558-561

Jass J, Sobin L (1989) Histological typing of intestinal tumours. In WHO International Classification of Tumours 2nd edn Berlin: Springer Verlag

Jass JR (1986) Lymphocytic infiltration and survival in rectal cancer. J Clin Pathol 39: $585-589$
Jass JR, Do KA, Simms LA, Iino H, Wynter C, Pillay SP, Searle J, RadfordSmith G, Young J, Leggett B (1998) Morphology of sporadic colorectal cancer with DNA replication errors. Gut 42: 673-679

Johannsdottir JT, Bergthorsson JT, Gretarsdottir S, Kristjansson AK, Ragnarsson G, Jonasson JG, Egilsson V, Ingvarsson S (1999) Replication error in colorectal carcinoma: association with loss of heterozygosity at mismatch repair loci and clinicopathological variables. Anticancer Res 19: $1821-1826$

Kim H, Jen J, Vogelstein B, Hamilton SR (1994) Clinical and pathological characteristics of sporadic colorectal carcinomas with DNA replication errors in microsatellite sequences. Am J Pathol 145: 148-156

Kinzler KW, Vogelstein B (1996) Lessons from Hereditary Colorectal Cancer. Cell 87: $159-170$

Klein J, Sato A (2000) The HLA system. First of two parts. N Engl J Med 343: $702-709$

Kunihiro M, Tanaka S, Haruma K, Yoshihara M, Sumii K, Kajiyama G, Shimamoto F (1998) Combined expression of HLA-DR antigen and proliferating cell nuclear antigen correlate with colorectal cancer prognosis. Oncology 55: $326-333$

Lazaris AC, Theodoropoulos GE, Davaris PS, Panoussopoulos D, Nakopoulou L, Kittas C, Golematis BC (1995) Heat shock protein 70 and HLA-DR molecules tissue expression. Prognostic implications in colorectal cancer. Dis Colon Rectum 38: 739-745

Lothe RA, Peltomaki P, Meling GI, Aaltonen LA, Nystrøm-Lahti M, Pylkkanen L, Heimdal K, Andersen TI, Møller P, Rognum TO, Fosså SD, Haldorsen T, Langmark F, Brøgger A, Chapelle Adl, Børresen A-L (1993) Genomic Instability in Colorectal Cancer: Relationship to Clinicopathological Variables and Family History. Cancer Res 53: 5849-5852

Loukola A, Eklin K, Laiho P, Salovaara R, Kristo P, Jarvinen H, Mecklin JP, Launonen V, Aaltonen LA (2001) Microsatellite marker analysis in screening for hereditary nonpolyposis colorectal cancer (HNPCC). Cancer Res 61: $4545-4549$

Lukish JR, Muro K, DeNobile J, Katz R, Williams J, Cruess DF, Drucker W, Kirsch I, Hamilton SR (1998) Prognostic significance of DNA replication errors in young patients with colorectal cancer. Ann Surg 227: 51-56

Massa MJ, Iniesta P, Gonzalez-Quevedo R, de Juan C, Caldes T, SanchezPernaute A, Cerdan J, Torres AJ, Balibrea JL, Benito M (1999) Differential prognosis of replication error phenotype and loss of heterozygosity in sporadic colorectal cancer. Eur J Cancer 35: 1676-1682

Meling GI, Rognum TO, Clausen OP, Chen Y, Lunde OC, Schlichting E, Wiig JN, Hognestad J, Bakka A, Havig O et al (1991) Association between DNA ploidy pattern and cellular atypia in colorectal carcinomas. A new clinical application of DNA flow cytometric study? Cancer 67: 1642-1649

Messerini L, Vitelli F, De Vitis LR, Mori S, Calzolari A, Palmirotta R, Calabro A, Papi L (1997) Microsatellite instability in sporadic mucinous colorectal carcinomas: relationship to clinico-pathological variables. J Pathol 182: $380-384$

Michael-Robinson JM, Biemer-Huttmann A, Purdie DM, Walsh MD, Simms LA, Biden KG, Young JP, Leggett BA, Jass JR, Radford-Smith GL (2001) Tumour infiltrating lymphocytes and apoptosis are independent features in colorectal cancer stratified according to microsatellite instability status. Gut 48: $360-366$

Morita M, Tanaka K, Kawanishi H, Tsuji M, Ookusa T, Takada H, Okamura A, Hioki K (1995) Immunohistochemically demonstrated expression of HLA-DR antigen in colorectal adenocarcinomas and its relation to clinicopathological features. J Surg Oncol 59: 233-238

Naito Y, Saito K, Shiiba K, Ohuchi A, Saigenji K, Nagura H, Ohtani H (1998) $\mathrm{CD} 8+\mathrm{T}$ cells infiltrated within cancer cell nests as a prognostic factor in human colorectal cancer. Cancer Res 58: $3491-3494$

Norheim Andersen S, Rognum TO, Lund E, Meling GI, Hauge S (1993) Strong HLA-DR expression in large bowel carcinomas is associeted with good prognosis. $\mathrm{Br} J$ Cancer 68: $80-85$

Rognum TO (1991) Near diploid large bowel carcinomas have better fiveyear survival than aneuploid ones. Cancer 68: 1077 - 1081

Rognum TO, Brandtzaeg P, Elgjo K, Fausa O (1987) Heterogeneous epithelial expression of class II (HLA-DR) determinants and secretory component related to dysplasia in ulcerative colitis. Br J Cancer 56: 419-424

Rognum TO, Brandtzaeg P, Thorud E (1983) Is heterogeneous expression of HLA-dr antigens and CEA along with DNA-profile variations evidence of phenotypic instability and clonal proliferation in human large bowel carcinomas? Br J Cancer 48: 543-551 
Rooney PH, Murray GI, Stevenson DA, Haites NE, Cassidy J, McLeod HL (1999) Comparative genomic hybridization and chromosomal instability in solid tumours. Br J Cancer 80: $862-873$

Ropponen KM, Eskelinen MJ, Lipponen PK, Alhava E, Kosma VM (1997) Prognostic value of tumour-infiltrating lymphocytes (TILs) in colorectal cancer. J Pathol 182: 318-324

Ruschoff J, Bocker T, Schlegel J, Stumm G, Hofstaedter F (1995) Microsatellite instability: new aspects in the carcinogenesis of colorectal carcinoma. Virchows Archiv 426: 215-222

Sæterdal I, Bjørheim J, Lislerud K, Gjertsen MK, Bukholm I, Olsen OC, Nesland JM, Eriksen JA, Møller M, Lindblom A, Gaudernack G (2001) Frameshift mutation derived peptides as new tumor specific antigenes in inherited and spontaneous colorectal cancer. Proc Nat Acad Sci 98: $13255-13260$

Salahshor S, Kressner U, Fischer H, Lindmark G, Glimelius B, Pahlman L, Lindblom A (1999) Microsatellite instability in sporadic colorectal cancer is not an independent prognostic factor. Br J Cancer 81: 190-193

Senba S, Konishi F, Okamoto T, Kashiwagi H, Kanazawa K, Miyaki M, Konishi M, Tsukamoto T (1998) Clinicopathologic and genetic features of nonfamilial colorectal carcinomas with DNA replication errors. Cancer 82: $279-285$

Smyrk TC, Watson P, Kaul K, Lynch HT (2001) Tumor-infiltrating lymphocytes are a marker for microsatellite instability in colorectal carcinoma. Cancer 91: $2417-2422$

Thibodeau SN, Bren G, Schaid D (1993) Microsatellite instability in cancer of the proximal colon. [see comments]. Science 260: 816-819
Thibodeau SN, French AJ, Cunningham JM, Tester D, Burgart LJ, Roche PC, McDonnell SK, Schaid DJ, Vockley CW, Michels VV, Farr Jr GH, O'Connell MJ (1998) Microsatellite instability in colorectal cancer: different mutator phenotypes and the principal involvement of hMLH1. Cancer Res 58: $1713-1718$

Thorstensen L, Diep CB, Meling GI, Aagensen T, Ahrens CH, Rognum TO, Lothe RA (2001) WNT1 inducible signaling pathway protein 3, WISP3, a novel target gene in colorectal carcinomas with microsatellite instability. Gastroenterology 121: 1275-1280

Ward R, Meagher A, Tomlinson I, O'Connor T, Norrie M, Wu R, Hawkins N (2001) Microsatellite instability and the clinicopathological features of sporadic colorectal cancer. Gut 48: 821-829

Watanabe T, Wu TT, Catalano PJ, Ueki T, Satriano R, Haller DG, Benson III AB, Hamilton SR (2001) Molecular predictors of survival after adjuvant chemotherapy for colon cancer. $N$ Engl J Med 344: 1196-1206

Wright CM, Dent OF, Barker M, Newland RC, Chapuis PH, Bokey EL, Young JP, Leggett BA, Jass JR, Macdonald GA (2000) Prognostic significance of extensive microsatellite instability in sporadic clinicopathological stage C colorectal cancer. Br J Surg 87: 1197- 1202

Zhou XP, Hoang JM, Li YJ, Seruca R, Carneiro F, Sobrinho-Simoes M, Lothe RA, Gleeson CM, Russell SE, Muzeau F, Flejou JF, Hoang-Xuan K, Lidereau R, Thomas G, Hamelin R (1998) Determination of the replication error phenotype in human tumors without the requirement for matching normal DNA by analysis of mononucleotide repeat microsatellites. Genes Chromosomes Cancer 21: 101-107 